\title{
Yöneylem Araştırması Alanında Yapılan Çalışmaların Bibliyometrik Analizi
}

\author{
Özlem Çomaklı Sökmen ${ }^{1 *}$, Mustafa Yılmaz ${ }^{2}$ \\ $\mathbf{1}^{*}$ Erzurum Teknik Üniversitesi, Sürekli Eğitim Uygulama ve Araştırma Merkezi, Erzurum, Türkiye, (ORCID: 0000-0001-8765-0038), ozlem.sokmen@ erzurum.edu.tr \\ ${ }^{2}$ Atatürk Üniversitesi, Mühendislik Fakültesi, Endüstri Mühendisliği Bölümü, Erzurum, Türkiye (ORCID: 0000-0002-2135-5762), mustafay@atauni.edu.tr
}

(1st International Conference on Applied Engineering and Natural Sciences ICAENS 2021, November 1-3, 2021)

(DOI: $10.31590 /$ ejosat.1012167)

ATIF/REFERENCE: Çomaklı Sökmen, Ö. \& Yılmaz, M. (2021). Yöneylem Araştırması Alanında Yapılan Çalışmaların Bibliyometrik Analizi. Avrupa Bilim ve Teknoloji Dergisi, (28), 940-946.

\section{Öz}

Yöneylem Araştırması (YA) karmaşık problemlerin tanımı, matematiksel olarak modellenmesi, çözümü ve optimal karar verme ile ilgilenen bir disiplindir. Bu araştırmanın amacı Web of Science (WOS) veri tabanında YA ile ilgili yapılan çalışmaların bibliometric analizini gerçekleştirmektir. Bu amaç doğrultusunda bu alandaki çalışmaların hangi yıllarda yoğunlaştığı, çalışmalarda en çok hangi anahtar kelimelerin kullanıldığı, özetlerde en fazla geçen kelimelerin neler olduğu ve çalışmaların hangi dilde yayınlandığına ilişkin analizler yapılmıştır. Ayrıca en çok atıf yapılan yazarlar, en çok atıf yapılan ülkeler ve en çok atıf yapılan dergilerin genel profilleri ortaya çıkarılmıştır. WOS veri tabanında araştırma kapsamına giren 6048 çalışma bibliyometrik analiz yöntemiyle incelenmiştir. Çalışmanın verileri 2021 yılı Ekim ayında toplanmıştır. VOSviewer programı kullanılarak yapılan analiz sonuçlarına göre araştırmalarda en çok kullanılan anahtar kelimelerin sırasıyla supply chain management (tedarik zinciri yönetimi), operations management (süreç yönetimi), sustainability (sürdürülebilirlik) olduğu sonucuna ulaşılmıştır. Özetlerde en çok kullanılan kelimeler ise time (zaman), problem, cost (maliyet) olarak sıralanmaktadır. Çalışma kapsamındaki çalışmaların yayın dilinin en çok sırasıyla English (İngilizce), Chinese (Çince) ve French (Fransızca) olduğu anlaşılmıştır. En çok ortak atıf alan yazarlar sırayla Ivanov ve Dubey'dir. En çok atıf alan üniversitenin ise Montpellier Business School olduğu ortaya çıkmıştır. Çalışmaların en çok Science Citation Index Expanded indeksine giren dergilerde yayınlandığı görülmüştür. Alanla ilgili yapılan çalışmaların yıllara göre en çok 2019'da gerçekleştirildiği görülmektedir. En çok atıf alan ülkelerin ise sırayla France (Fransa), USA (Amerika Birleşik Devletleri) ve England (İngiltere) olduğu ortaya çıkmıştır. Elde edilen sonuçların YA ilgili araştırma yapmak isteyen araştırmacılara genel bir bakış açısı sunacağı düşünülmektedir.

\section{Bibliometric Analysis of the Studies Performed in Operations Research Field}

\begin{abstract}
Operations Research (OR) is a field concerned with the formulation, mathematical modeling, solution, and optimization of complex problems. This study aims to discover OR publications in the Web of Science (WOS) database to perform bibliometric analysis. To this end, analyses were conducted on the years in which the majority of research in this area was completed, the most frequently used keywords in the studies, the most commonly used terms in the abstracts, and the language in which the papers were published. Also, the most often cited authors, countries, and general characteristics of the most frequently cited journals were uncovered. Of those studies in the WOS database, 6048 studies included in the scope of the research were analyzed using the bibliometric analysis method. The current study's data were collected in October 2021. According to the analysis performed using the VOSviewer software, the most often used terms in the literature are supply chain management, operations management, and sustainability. The most frequently used words in the abstracts are listed as time, problem, cost. The analysis also showed that the publication languages of the studies examined within the scope of the study are mostly English, Chinese and French. The most commonly cited authors are Ivanov and
\end{abstract}


Dubey, respectively. Montpellier Business School was found to be the most frequently mentioned university. It has been noted that the majority of the studies were published in journals that are part of the Science Citation Index Expanded. According to the years, the majority of studies in this area were performed in 2019. It has been revealed that the most cited countries are France, the USA (United States), and England. The results are expected to offer a groundwork for academics interested in conducting OR.

Keywords: Operations research, Bibliometric analysis, Industrial engineering, Citation analysis, Network analysis, VOSviewer.

\section{Giriş}

Yöneylem, karmaşık sorunların çözümünde ve incelenmesinde bilimsel ve özellikle matematiksel yöntemlerin uygulanışı; Yöneylem Araştırması (YA) ise; herhangi bir problemi yöneylem yöntemine göre araştıran incelemedir [1].

YA insan, makine, para ve malzemeden oluşan endüstriyel, ticari, kamu, özel ve askeri sistemlerin yönetiminde karşılaşılan problemleri bilimsel yöntem yaklaşımı ile çözmeyi ele alan ve ele aldığı sistemleri geliştirmeyi amaçlayan bir bilim dalıdır. YA bir bilim olarak 1930'ların ikinci yarısında Alman hava kuvvetlerinin saldırılarına karşılık vermek ve askeri operasyonların etkinliğini optimum kılmak amacıyla İngiliz Ordusunda kullanılmaya başlanmıştır [2]. İngiltere'de savaş araç-gereçlerinin daha kısa sürede gemilere yüklenip boşaltılmasını sağlayacak bir yöntem aranmaya başlanmış; bu karmaşık problemleri çözmek ve muharebelerdeki etkinliği artırmak farklı bilim dallarından oluşan ekiplerle çalışılmıştır [3]. Söz konusu askeri operasyonlarda bilimsel metotların araştırılması ve uygulanması işlemi Operations Research (Yöneylem Araştırması) olarak adlandırılmıştır.

Genellikle kıt kaynakların dağıtımı ve karar problemleri ile ilgilenen YA, problemlerin optimal veya optimale yakın çözümlerine ulaşmak için bir çok teknik ve bilimsel yöntemi kullanmaktadır. Dolayısıyla YA disiplinler arası bir yaklaşım olup; matematik, mühendislik, istatistik, iktisat gibi birçok alanda karşımıza çıkmaktadır.

YA’nın üç ana özelliği vardır [3]:

- $\quad$ sistem yaklaşımı (bütünleşik yaklaşım),

- disiplinler arası yaklaşım,

- bilimsel yaklaşım.

YA bir problemi ele alırken problemin ait olduğu organizasyonun tüm bileşenlerini gözetmektedir. $\mathrm{Bu}$ gözetimi yaparken örgütün çevresini ve bileşenler arasındaki etkileşimi de göz önünde bulundurmaktadır. Çünkü örgütün herhangi bir birimindeki değişiklik tüm birimleri etkileyebilmektedir. Bu sebeple bütünleşik yaklaşımla tüm bileşenlerin incelenmesi gerekir.

YA problemlerinin çoğu matematik, istatistik gibi uzmanlık alanları farklı olan kişilerden oluşan bir ekiple modellenmesi ve çözülmesi gereken karmaşık problemlerdir. Bu da YA'nın disiplinler arası bir yaklaşım olma özelliğini ortaya koymaktadır.

En basit haliyle bilimsel yöntem ise; ele alınan problemlerin çözümünde bir bilimsel yaklaşımın kullanılmasını belirtmektedir. YA'nın kullandığı bilimsel yöntem aşağıda sıralanan adımlardan oluşmaktadır[3]:

1. Problemin belirlenmesi,

2. Gerekli verilerin elde edilmesi,

3. Modelin geliştirilmesi,

4. Modelden çözüm elde edilmesi,

5. Modelin geçerliliğinin test edilmesi

6. Modelin uygulanması ve karar.
II. Dünya Savaşı'nı izleyen ilk yıllarda fazla gelişim gösteremeyen YA, son yıllarda bilim dünyasının en gözde konuları arasında yer almıştır. YA, dünya çapında birçok kuruluşun etkinliğinin ve çok sayıda ülkenin ekonomik verimliliğinin artırılmasında büyük katkılar sağlamıştır [3]. Öyle ki birçok ülke YA'nın gelişimine katkı sağlamak ve endüstride uygulanabilirliğini yaygınlaştırmak için kendi ulusal Yöneylem Araştırması Derneklerini kurmuşlar ve dergi yayınlarını başlatmışlardır.

YA birçok alanda yaygın olarak kullanılmaktadır. Üretim planlama, toplam kalite yönetimi, malzeme ve envanter yönetimi, taşıma/ulaşım, optimizasyon, benzetim, kaynak planlaması, kriz yönetimi, savunma planlarının oluşturulması, maliyet analizi, karar modelleri, stratejik planlama ve verimlilik analizi bu kapsama giren alanlar arasında sıralanabilir.

YA'da kullanılan teknikler modellerin yapısına göre değişkenlik göstermekle birlikte temel olarak deterministik ve olasılıklı modeller olarak gruplandırılabilir [4]. Deterministik model tipi için doğrusal programlama, tam sayılı programlama, hedef programlama, analitik hiyerarşi süreci, ulaştırma ve atama modelleri, doğrusal olmayan programlama, deterministik dinamik programlama, deterministik stok modelleri, şebeke analizi gibi yöntemler kullanılmaktadır. Olasılıklı modellerde ise; markov zincirler, kuyruk teorisi, karar analizi, oyun teorisi, simülasyon, tahmin modelleri, olasılıklı stok modelleri, olasılıklı dinamik programlama kullanılan yöntemler arasındadır [3], [4].

YA’nın farklı alanlarda yapılan çalışmalarının bir kısmına bu bölümde yer verilmiştir. Levine and Dunn çalışmalarında sağlık çizelgeleme problemi için YA kullanmışlardır. Hastaların etkin hizmet alması ve verimliliği sağlamak adına hastane genelinde kaynak planlaması oluşturmak için çalışmada dinamik modelleme yöntemleri kullanılmıştır [5]. Molina-Pariente et al. yaptıkları çalışmada ameliyathane çizelgeleme problemini ele almışlardır. Çalışmada ameliyat süresi, acil ameliyatların gelişi, cerrah kapasitedeki belirsizlikler nedeniyle problem stokastik bir yaklaşım ile ele alınarak çözüm için Monte Carlo optimizasyon yöntemi önerilmiştir [6]. Davis et al. çalışmalarında böbrek nakillerinde coğrafi kısıtlar kaynaklı, eşitlikçi olmayan atamaların önlenmesi problemini ele almış ve karma tam sayılı doğrusal programlama ile çözüme kavuşturmuştur [7]. Literatürde mühendislik alanında da çok sayıda ulaştırma ve rotalama probleminin çözümünde YA'dan yararlanıldığg görülmektedir. Perrier et al. çalışmalarında kar temizleme operasyonları için bir araç rotalama problemini ele almış ve problemin çözümüne yönelik iki sezgisel çözüm yaklaşımı sunmuşlardır [8]. Filho and Junqueria çalışmalarında bir ayrıt rotalama problemi olan Çinli Postacı Probleminin çözüm yöntemini seçmeye yönelik bir algoritma önermişlerdir. Önerilen algoritma Brezilya'da çöp toplama hizmeti ve postane posta dağıtımı olmak üzere iki lojistik problem vakasında kullanılmıştır [9]. Price and Ostfeld su dağıtım sistemlerinde doğrusal olmayan programlama metodunu kullanarak elektrik işletme maliyetlerinin minimum düzeye indirilebileceğini belirtmişlerdir [10]. Özkan ve Sezen çalışmalarında eğitim sistemi kavramını sistem yaklaşımı ile ele alarak problemlere bu 
yaklaşımla çözüm getirilmesini önermişlerdir [11]. Bunların dışında tarım, bankacılık, tekstil, ormancılık, balıkçılık ve madencilik gibi birçok sektörde de YA tekniklerinin yaygın olarak kullanıldığı görülmektedir [12] - [18].

Görüldüğü üzere literatürde YA ile ilgili oldukça fazla çalışma bulunmaktadır. Fakat Endüstri Mühendisliği alanında günümüze kadar yapılan çalışmalar için YA'yı bibliyometrik göstergeler bakımından ele alan herhangi bir araştırmaya rastlanılmamıştır. Literatürde disiplinler arası çalışılan konuların bibliyometrik çalışmayla incelenmesi önemlidir. Zira bibliyometrik araştırmayla varılan sonuçlar literatüre genel bir bakış sağlamakta ve bu konuda yapılacak çalışmalarda yönlendirici bir etkiye sahip olacaktır [19]. Bu doğrultuda bu çalışmada YA konusunda yapılan çalışmalarla ilgili aşağıdaki sorulara cevap aranmıştır:

- Doküman türlerinin dağılımı nasıldır?

- Yayın dillerinin dağılımı nasıldır?

- Yayın yıllarının dağılımı nasıldır?

- En çok kullanılan anahtar kelimelerin dağılımı nasildir?

- En çok kullanılan anahtar kelimelerin yıllara göre dağılımı nasıldır?

- En çok atıf alan ülkelerin dağılımı nasıldır?

- En çok atıf alan kurumların dağılımı nasıldır?

- En çok atıf alan dergilerin dağılımı nasıldır?

- En çok atıf alan yazarların dağılımı nasıldır?

- Özette en çok kullanılan kelimelerin dağılımı nasildir?

- Özette en çok kullanılan kelimelerin yallara göre dağılımı nasıldır?

\section{Materyal ve Metot}

$\mathrm{Bu}$ çalışma Web of Science (WOS) veri tabanında YA ile ilgili yapılan çalışmaların bibliyometrik analizini kapsamaktadır.

İlk kez 1922'de E. Wyndham Hulme tarafindan istatistiksel kaynakça terimi olarak kullanılan bibliyometri; farklı alanlarda yapılmış çalışmaların belirlenen başlıklara göre analiz edilmesi, bu analizler sonucunda ortaya çıkan sonuçların değerlendirilmesi ve yorumlanmasidir [20], [21].

Çalışma kapsamında YA ile ilgili çalışmaların bibliyometrik analizini yapmak için WOS veri tabanına "operations research" anahtar kelimesi girilerek veri tabanında bulunan çalışmalara ulaşılmıştır (12 Ekim 2021). Daha sonra ise kategori olarak Endüstri Mühendisliği seçilmiş ve bu kapsamda araştırmanın amacına uygun 6048 çalışma analiz için hazır hale getirilmiştir.

Çalışmadaki analizler VOSviewer programı kullanılarak yapılmıştır. $\mathrm{Bu}$ analizlerde; yayın dillerinin ve yıllarının dağılımı, YA alanında yapılan çalışmalarda en çok atıf alan yazar, ülke ve dergilerin dağılımı ve YA konusunda en çok kullanılan anahtar kelimeler ve özetlerde geçen anahtar kelimelerin dağılımı ile ilgili verilere ilişkin sonuçlar tablolar ve görsellerle desteklenerek verilmiştir.

\section{Araştırma Sonuçları ve Tartışma}

$\mathrm{Bu}$ bölümde analiz sonuçlarına göre düzenlenen tablolar, VOSviewer programı aracılığıyla elde edilen görseller ile bunların yorumları yer almaktadır.

\subsection{Doküman Türü, Yayın Dili ve Yayın Yıllarına İlişkin Bulgular}

Çalışma kapsamında ele alınan 6048 çalışmanın türleri incelendiğinde en çok (f=3349) makale çalışması yapıldığ görülmektedir.

Söz konusu 6048 çalışmanın English (İngilizce) (f=6007); Chinese (Çince) $(\mathrm{f}=28)$; French (Fransızca) ( $\mathrm{f}=6)$; German (Almanca) $(\mathrm{f}=5)$; Spanish (İspanyolca) $(\mathrm{f}=1)$ ve Welsh (Galce) $(\mathrm{f}=1)$ dillerinde yayınlandığ

Konu ile ilgili Endüstri Mühendisliği alanında ilk çalışma 1972 yılında yapılmış olup, araştırma kapsamına giren çalışmaların 2019 (f=507) yılında yoğunlaştığı görülmektedir. Çalışma sayılarının yıllara göre dağılımı Şekil 1'de verilmiştir.

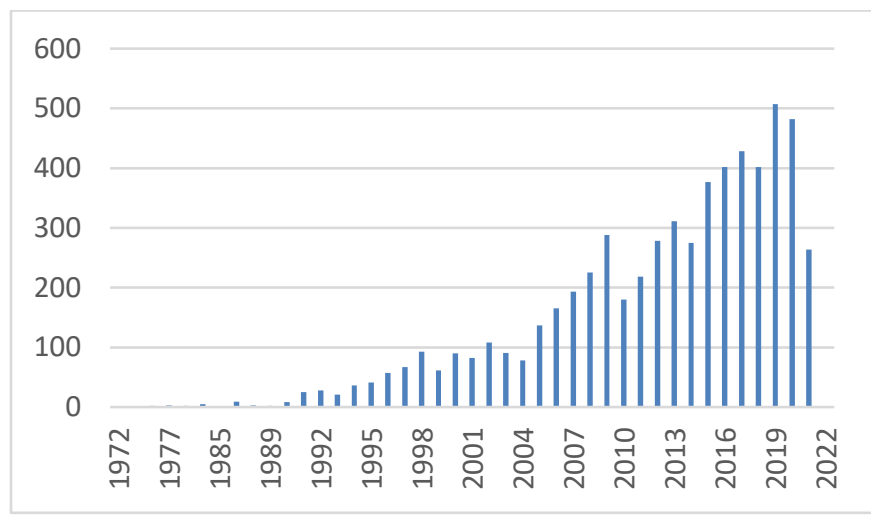

Şekil 1. Çalışma sayılarının yıllara göre dağılımı

\subsection{En Çok Atıf Alan Anahtar Kelimelerin Dağılımı}

Araştırma kapsamında ele alınan çalışmalarda en çok kullanılan anahtar kelimeler belirlenmiştir. Elde edilen harita Şekil 2'de gösterilmiştir. Buna göre en çok kullanılan kelimeler arasında supply chain management (tedarik zinciri yönetimi) $(\mathrm{f}=21)$, operations management (süreç yönetimi) ( $\mathrm{f}=19)$, sustainability (sürdürülebilirlik) $(\mathrm{f}=18)$, systematic literature review (sistematik literatür taraması) $(\mathrm{f}=16)$, industry 4 (endüstri 4) $(\mathrm{f}=15)$ yer almaktadır. YA ile ilgili çalışmalarda en çok kullanılan 14 anahtar kelime Tablo 1'de; en çok kullanılan anahtar kelimelerin ağ yapısı Şekil 2'de ve en çok kullanılan anahtar kelimelerin yıllara göre dağılımı ise Şekil 3'te sunulmuştur.

Tablo 1. Çalışmalarda en çok kullanılan 14 anahtar kelime

\begin{tabular}{|c|c|c|c|}
\hline Anahtar Kelime & $\mathbf{f}$ & $\begin{array}{c}\text { Anahtar } \\
\text { Kelime }\end{array}$ & $\mathbf{f}$ \\
\hline $\begin{array}{c}\text { Supply Chain } \\
\text { Management } \\
\text { (Tedarik Zinciri Yönetimi) }\end{array}$ & 21 & $\begin{array}{c}\text { Artificial } \\
\text { Intelligence } \\
\text { (Yapay Zekâ) }\end{array}$ & 13 \\
\hline $\begin{array}{c}\text { Operations Management } \\
\text { (Süreç Yönetimi) }\end{array}$ & 19 & $\begin{array}{c}\text { Logistics } \\
\text { (Lojistik) }\end{array}$ & 12 \\
\hline $\begin{array}{c}\text { Sustainability } \\
\text { (Sürdürülebilirlik) }\end{array}$ & 18 & $\begin{array}{c}\text { Simulation } \\
\text { (Simülasyon) }\end{array}$ & 12 \\
\hline $\begin{array}{c}\text { Systematic Literature } \\
\text { Review } \\
\text { (Sistematik Literatür } \\
\text { Taramas1) }\end{array}$ & 16 & $\begin{array}{c}\text { Blockchain } \\
\text { (Blok Zincir) }\end{array}$ & 12 \\
\hline $\begin{array}{c}\text { Industry 4 } \\
\text { (Endüstri 4) }\end{array}$ & 15 & $\begin{array}{c}\text { Machine } \\
\text { Learning }\end{array}$ & 12 \\
\hline
\end{tabular}




\begin{tabular}{|c|c|c|c|}
\hline & & $\begin{array}{c}\text { (Makine } \\
\text { Öğrenmesi) }\end{array}$ & \\
\hline $\begin{array}{c}\text { Safety } \\
\text { (Güvenlik) }\end{array}$ & 14 & $\begin{array}{c}\text { Industry 4.0 } \\
\text { (Endüstri 4.0) }\end{array}$ & 11 \\
\hline $\begin{array}{c}\text { Operations Research } \\
\text { (Yöneylem Araştırmas1) }\end{array}$ & 14 & $\begin{array}{c}\text { Risk } \\
\text { Management } \\
\text { (Risk Yönetimi) }\end{array}$ & 11 \\
\hline
\end{tabular}

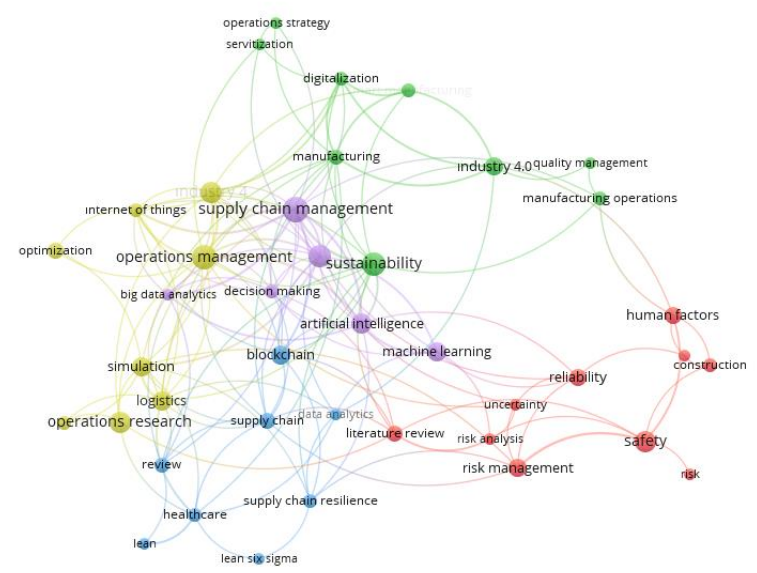

Şekil 2. En çok kullanılan anahtar kelimelerin ă̆ yapısı

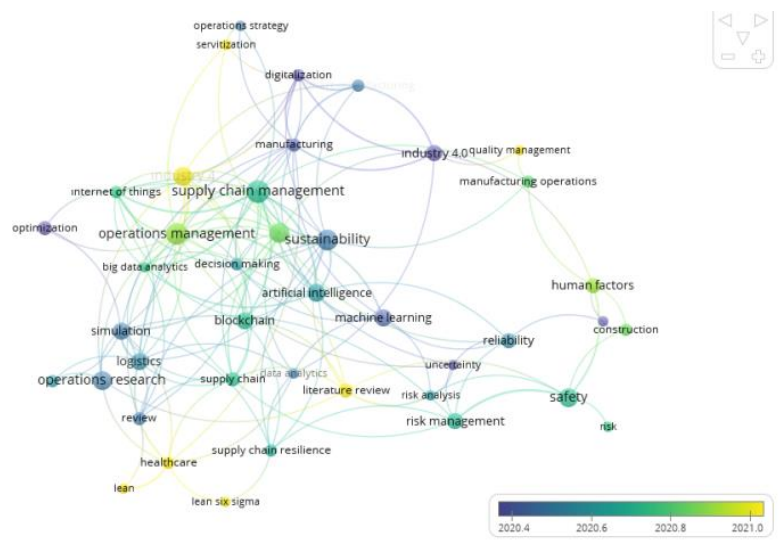

Şekil 3. En çok kullanılan anahtar kelimelerin yıllara göre dă̆llımı

\subsection{En Çok Atıf Alan Anahtar Ülkelerin Dağılımı}

Çalışma kapsamında ele alınan çalışmalarda en çok atıf alan ülkeleri belirlemek için VOSviewer yazılım aracında bibliyometrik ağ yapıları elde edilmiştir. Buna göre çalışma kapsamında en çok atıf alan ülkeler Tablo 2'de; oluşturulan harita ise Şekil 4'te sunulmuştur.

Tablo 2. Doküman ve yayın atıflarına göre ülkeler

\begin{tabular}{|c|c|c|}
\hline Ülke & Doküman & Atıf sayısı \\
\hline France (Fransa) & 40 & 549 \\
\hline USA (ABD) & 105 & 508 \\
\hline England (İngiltere) & 75 & 348 \\
\hline Germany (Almanya) & 24 & 339 \\
\hline China (Çin) & 120 & 308 \\
\hline Italy (İtalya) & 26 & 126 \\
\hline India (Hindistan) & 26 & 105 \\
\hline Canada (Kanada) & 28 & 76 \\
\hline Sweden (İsveç) & 17 & 71 \\
\hline Brazil (Brezilya) & 31 & 63 \\
\hline Austria (Avusturya) & 5 & 58 \\
\hline Norway (Norveç) & 17 & 53 \\
\hline
\end{tabular}

\begin{tabular}{|c|c|c|}
\hline Australia (Avustralya) & 29 & 53 \\
\hline Spain (İspanya) & 14 & 47 \\
\hline Netherlands (Hollanda) & 16 & 33 \\
\hline Portugal (Portekiz) & 7 & 33 \\
\hline Finland (Finlandiya) & 13 & 31 \\
\hline Turkey (Türkiye) & 13 & 30 \\
\hline Wales (Galler) & 8 & 29 \\
\hline
\end{tabular}

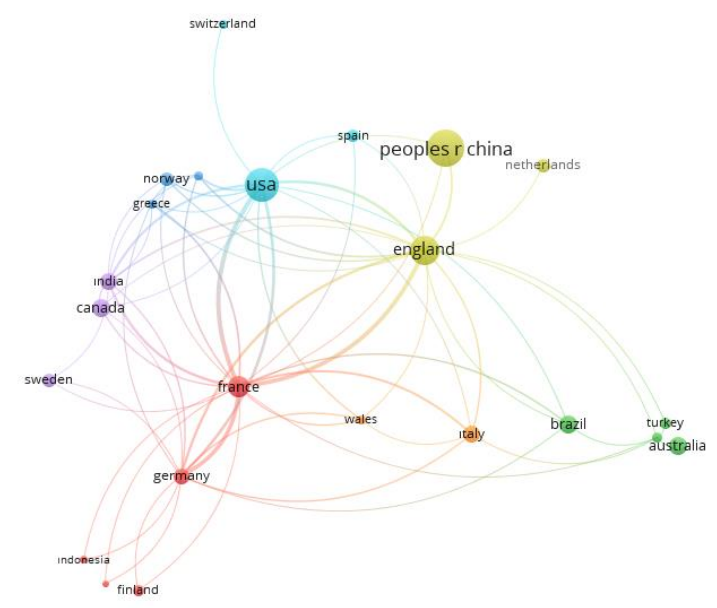

Şekil 4. En çok atıf alan ülkelerin ă̆ yapısı

Buna göre ilgili alanda en fazla atıf alan ülkeler arasında France (Fransa) (Atıf sayısı=549, Doküman=40); USA (ABD) (Atıf sayıs1=508, Doküman=105) ve England (İngiltere) (Atıf sayıs1=348, Doküman=75) gelmektedir.

\subsection{En Çok Atıf Alan Kurum ve Dergilerin Dağılımı}

Çalışma kapsamında ele alınan çalışmalarda en fazla atıf alan kurumlar arasinda Montpellier Business School (Atıf sayısı181, Doküman =7), The Hong Kong Polytechnic University (Atıf sayıs1=52, Doküman =13), Politecnico di Milano University (Atıf sayısı=40, Doküman=10), Loughborough University (Atıf sayısı=24, Doküman =6) ve Shanghai Jiao Tong University (Atıf sayısı=23, Doküman =7) bulunmaktadır.

En çok atıf alan dergiler incelendiğinde ise International Journal of Production Research (Atıf sayıs1=1441), International Journal of Production Economics (Atıf sayıs1=1281), European Journal of Operational Research (Atıf say1s1=762), Journal of Operations Management (Atıf sayısı=595), Production Planning \& Control (Atıf sayısı=563) gelmektedir. Bunun yanı sıra VOSviewer programında en çok atıf alan dergiler için oluşturulan ağ yapısı Şekil 5'te gösterilmiştir. 


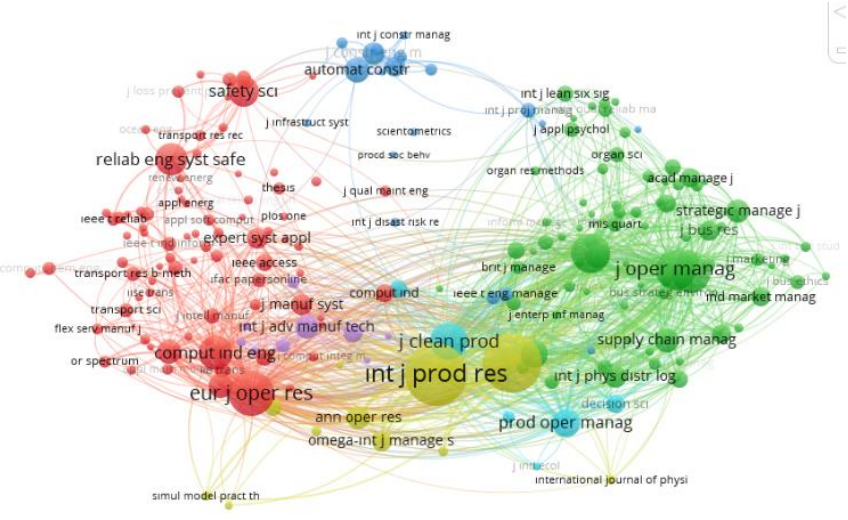

Şekil 5. En çok atıf alan dergilerin ăg yapısı

Çalışmaların en çok Science Citation Index Expanded $(\mathrm{f}=3413)$ indeksine giren dergilerde yayınlandığ 1 dikkat çekmiştir.

\subsection{En Çok Atıf Alan Yazarların Dağılımı}

En çok atıf alan yazarlar için yapılan analiz sonuçlarına göre Ivanov (Atıf sayısı=127), Dubey (Atıf sayısı=100), Choi (Atıf sayısı=50), Wamba (Atıf sayısı=48), Dolgui (Atıf sayısı=46) gibi araştırmacılar ilk sıralarda yer almaktadırlar. Çalışma kapsamında en çok atıf alan 20 yazar Tablo 3'de, ilgili ağ yapısı ise Şekil 6'dasunulmuştur.

Tablo 3. En çok atıf alan yazarlar

\begin{tabular}{|c|c|c|c|}
\hline Yazar & Atıf sayısı & Yazar & Atuf sayısı \\
\hline Ivanov & 127 & Porter & 33 \\
\hline Dubey & 100 & Yin & 28 \\
\hline Choi & 50 & Antony & 28 \\
\hline Wamba & 48 & Barney & 27 \\
\hline Dolgui & 46 & Ketokivi & 27 \\
\hline Christopher & 42 & Holmstrom & 27 \\
\hline Gunasekaran & 38 & Queiroz & 26 \\
\hline Tranfield & 34 & Altay & 25 \\
\hline Podsakoff & 33 & Atasu & 25 \\
\hline Teece & 33 & Govindan & 25 \\
\hline
\end{tabular}

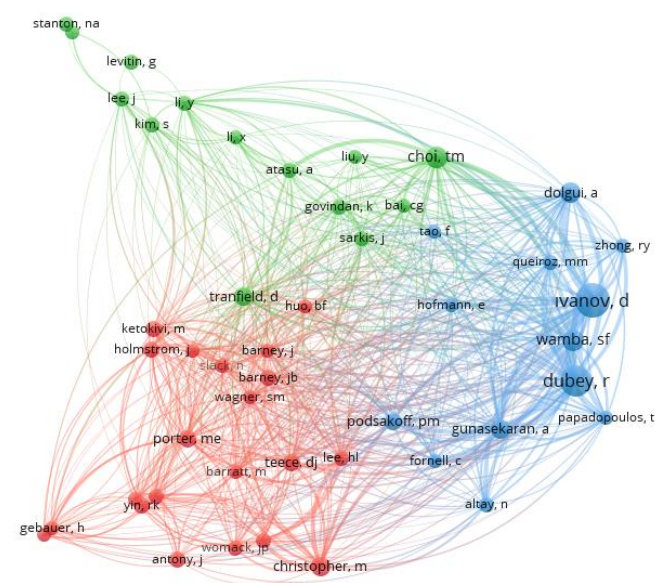

Şekil 6. En çok atıf alan yazarlara ilişkin ă̆ yapısı

\section{6. Özet Kısmında En Çok Kullanılan Kelimelerin Dağılımı}

Çalışmanın bu bölümünde özette en sık kullanılan kelimeler için analiz yapılmıştır. Buna göre özette en sık kullanılan 16 kelime Tablo 4'te; yine özet kısmında en çok kullanılan kelimeler için oluşturulan ağ yapısı ise Şekil 7'de verilmiştir.

Tablo 4. Özette en sik kullanılan kelimeler

\begin{tabular}{|c|c|c|c|}
\hline Kelime & f & Kelime & f \\
\hline Time (Zaman) & 104 & Effect (Etki) & 67 \\
\hline Problem & 103 & $\begin{array}{c}\text { Algorithm } \\
\text { (Algoritma) }\end{array}$ & 64 \\
\hline Cost (Maliyet) & 82 & $\begin{array}{c}\text { Relationship } \\
\text { (İlişki) }\end{array}$ & 62 \\
\hline Solution (Çözüm) & 76 & $\begin{array}{c}\text { Opportunity } \\
\text { (Fırsat) }\end{array}$ & 62 \\
\hline $\begin{array}{c}\text { Design } \\
\text { Methodology } \\
\text { Approach (Tasarım } \\
\text { Metodolojisi } \\
\text { Yaklaşımı) }\end{array}$ & 76 & Role (Rol) & 61 \\
\hline $\begin{array}{c}\text { Originality Value } \\
\text { (Özgünlük Değeri) }\end{array}$ & 74 & Article (Makale) & 57 \\
\hline Manager (Yönetici) & 72 & Theory (Teori) & 56 \\
\hline $\begin{array}{c}\text { Supply Chain } \\
\text { (Tedarik Zinciri) }\end{array}$ & 67 & $\begin{array}{c}\text { Practitioner } \\
\text { (Uygulayic1) }\end{array}$ & 56 \\
\hline
\end{tabular}

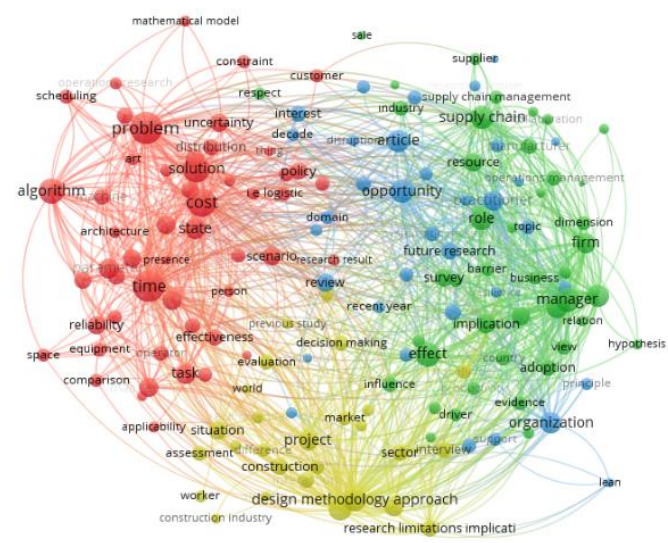

Şekil 7. Özette en çok kullanılan kelimelere ilişkin ăg yapısı

Ayrıca özet kısmında en çok kullanılan kelimelerin yıllara göre dağılımı Şekil 8'de sunulmuştur.

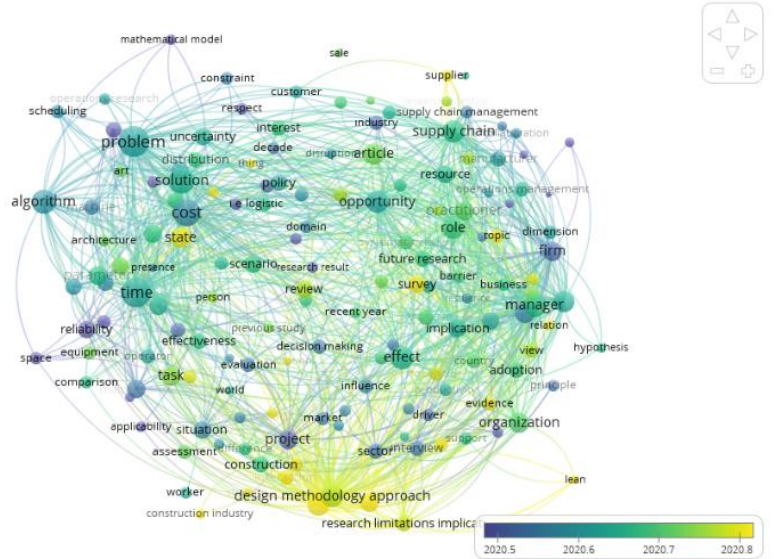

Şekil 8. Özette en çok kullanılan kelimelerin yıllara göre dağılımı

Bu çalışmada YA ile ilgili Endüstri Mühendisliği alanında yapılan 6048 çalışmaya ulaşılmış ve VOSviewer programı aracılığıyla bu çalışmaların bibliyometrik analizi yapılmıştır. Çalışma kapsamında ele alınan YA ile ilgili çalışmalar çeşitli 
değişkenler açısından değerlendirilmiştir. İlgili literatür incelendiğinde bu alanda çok sayıda çalışma bulunmasına karşın daha önce YA'nın 1972'den günümüze kadar Endüstri Mühendisliği kategorisinde yapılmış araştırmaları için bibliyometrik analizi ile ilgili bir çalışma yapılmadığı görülmüştür. Dolayısıyla bu çalışmanın ilgili alanda yapılan ilk çalışma olması, elde edilen sonuçların gelecekte bu konuda çalışma yapacak olan araştırmacılara yol göstermesi ve katkı sağlaması amaçlanmaktadır.

\section{Sonuç}

Endüstri Mühendisliğinin temel konularından biri olan ve genellikle gerçek hayat problemleri ile ilgilenen YA günümüzde birçok sektörde de yaygın bir şekilde kullanılmaktadır. $\mathrm{Bu}$ çalışmada YA ile ilgili WOS veri tabanındaki 6048 çalışmanın VOSviewer programı ile bibliyometrik analizi yapılmıştır. Bibliyometrik analiz, bilimsel veri tabanlarındaki kodlanmış bibliyografik bilgileri, yayın ve alıntı verilerindeki eğilimleri, yazarların, kurumların ve ülkelerin alanın gelişimine katkısı ve aralarındaki bilimsel işbirlikçi ağları ve yayınların dergiler arasında dağılımını incelemek için kullanılmaktadir [22]. Bu çalışmada YA alanında çalışma yapan araştırmacıların bu konuya katk1 düzeyleri, bu alanda yapılan yayınların yıllara göre dağılımı, yayın dilleri, hangi yazarların, ülkelerin, dergilerin ve kurumların en fazla atıf aldığı ve konuya daha fazla eğildiği ortaya konulmuştur. Ayrıca en çok atıf alan anahtar kelimeler ve özette en sık geçen kelimeler saptanarak bunların yıllara göre dağılımı da incelenmiştir.

$\mathrm{Bu}$ kapsamda ilk olarak doküman türleri incelendiğinde toplam çalışmaların \%55'inin makalelerden oluştuğu görülmektedir. En çok kullanılan yayın dili ise \%99 oranla English (İngilizce)dir. Bu durumun İngilizcenin uluslararası araştırma ve akademik yayıncılık dili olarak kabul edilmesinden kaynaklandığı söylenebilir [19],[23].

Çalışma kapsamında veri tabanındaki ilk çalışma 1972 yılında yapılmıştır. Son yıllarda yapılan çalışma sayılarında artış olduğu söylenebilir. Çalışmalarda en çok kullanılan anahtar kelimeler arasında supply chain management (tedarik zinciri yönetimi), operations management (süreç yönetimi), sustainability (sürdürülebilirlik) gibi YA ile ilgili kelimelerin yer aldığı saptanmıştır. Keza çalışmalarda kullanılan anahtar kelimeler çalışma alanı ve içeriğine uygun olmalıdır.

Çalışma kapsamında en çok atıf alan yazarlar 127 ve 100 atıfla sırasıyla Ivanov ve Dubeydir. Söz konusu yazarların alana yön veren çalışmalar yaptıkları söylenebilir. YA ile ilgili yapılan çalışmaların en çok atıfta bulunduğu dergi 1441 atıf ile International Journal of Production Research dergisidir. $\mathrm{Bu}$ dergiyi sırasiyla 1281 atıfla International Journal of Production Economics ve 762 atıfla European Journal of Operational Research dergileri izlemektedir. $\mathrm{Bu}$ dergilerin YA alanı için akademik olarak önemli olduğu söylenebilir.

$\mathrm{Bu}$ çalışmanın YA ile ilgili araştırma yapacak olan araştırmacılar için genel bir çerçeve sunması amaçlanmaktadır. Çalışma kapsamında elde edilen sonuçlardan yola çıkarak sonraki çalışmalar için bir takım öneriler sunulabilir:

- $\quad \mathrm{Bu}$ alanla ilgili farklı veri tabanlarındaki çalışmalar analizlere dahil edilerek incelenebilir.

- Citespace, Gephi, R Studio gibi farklı haritalama ve görselleştirme programları kullanılarak daha farkl1 analizler yapılabilir.
- Araştırmacılar, YA ile ilgili yapacakları çalışmalarda bu çalışmanın sonuçlarından faydalanarak YA alanında yapılan bibliyometrik analizlerden elde edilen sonuçlara göre çalışmalarına yön verebilirler.

- $\quad \mathrm{Bu}$ alanda en sik kullanılan anahtar kelimelerin yıllara göre dağılımı incelenerek YA'nın güncel konuları ile ilgili bilgi edinilebilirler.

- Ayrıca alandaki boşluklar tespit edilerek ilerleyen süreçte yapılması planlanan çalışmalar için katkı sağlanabilir.

\section{Kaynakça}

[1] Kurumu, T.D. (2021). Türk dil kurumu sözlükleri. Erişim adresi: https://sozluk. gov. tr.

[2] Öztürk, A. (2013). Yöneylem Araştırmasının Tarihi Gelişimi ve Özellikleri. Alphanumeric Journal, 1(1), 1-11.

[3] Demirer, Ö., \& Alkan, R.M. (2015). Mühendislik Uygulamalarında Yöneylem Araştırması Tekniklerinin Kullanımı. TMMOB Harita ve Kadastro Mühendisleri Odası, 15. Türkiye Harita Bilimsel ve Teknik Kurultayı, Ankara.

[4] Taha, H.A. (2007). Yöneylem Araştırması, 6. basım. Literatür Yayıncılık, İstanbul, Türkiye.

[5] Levine, W.C., \& Dunn, P.F. (2015). Optimizing Operating Room Scheduling. Anesthesiology Clinics, 33(4), 697-711.

[6] Molina-Pariente, J.M., Hans, E.W., \& Framinan, J.M. (2018). A stochastic approach for solving the operating room scheduling problem. Flexible Services and Manufacturing Journal, 30(1), 224-251.

[7] Davis, A.E., Mehrotra, S., Friedewald, J.J., Daskin, M.S., Skaro, A.I., Abecassis, M.M., \& Ladner, D.P. (2015). Improving geographic equity in kidney transplantation using alternative kidney sharing and optimization modeling. Medical Decision Making, 35(6), 797-807.

[8] Perrier, N., Langevin, A., \& Amaya, C. A. (2008). Vehicle routing for urban snow plowing operations. Transportation Science, 42(1), 44-56.

[9] Godinho Filho, M., \& Ribeiro Junqueira, R. D. A. (2010). Chinese Postman Problem (CPP): solution methods and computational time. International Journal of Logistics Systems and Management, 7(3), 324-344.

[10] Price, E., \& Ostfeld, A. (2013). Iterative linearization scheme for convex nonlinear equations: application to optimal operation of water distribution systems. Journal of Water Resources Planning and Management, 139(3), 299312.

[11] Özkan, E., \& Sezen, H. K. (2017). Toplum için yöneylem araştırması: Eğitimin yönetiminde sistem yaklaşımı uygulaması. Uludağ Üniversitesi İktisadi ve İdari Bilimler Fakültesi Dergisi, 36(1), 83-109.

[12] Asan, Ü. (1980). Yöneylem araştırma metodlarının ormancılıkta kullanılabileceği ve bazı uygulama alanlar1. Journal of the Faculty of Forestry Istanbul University, 30(2), 184-195.

[13] Topuz, E., \& Nasuf, E. (1991). Madencilik Endüstrisinde Yöneylem Araştırması Uygulamaları. Bilimsel Madencilik Dergisi, 30(2), 15-20.

[14] Pamukçu, D. (2002). Kuyruk teorisinin bir bankanın çağrı merkezi için uygulaması. Doktora tezi, Marmara Üniversitesi Sosyal Bilimler Enstitüsü, İstanbul, Türkiye. 
[15] Daşdemir, İ., \& Güngör, E. (2002). Çok boyutlu karar verme metotları ve ormancılıkta uygulama alanları. Bartın Orman Fakültesi Dergisi, 4(4), 1-19.

[16] Ertuğrul İ. (2005). Bulanık Hedef Programlama ve Bir Tekstil Firmasında Uygulama Örneği. Eskişehir Osmangazi Üniversitesi Sosyal Bilimler Dergisi, 6(2), 4578.

[17] Bjørndal, T., Herrero, I., Newman, A., Romero, C., \& Weintraub, A. (2012). Operations research in the natural resource industry. International Transactions in Operational Research, 19(1-2), 39-62.

[18] Carravilla, M. A., \& Oliveira, J. F. (2013). Operations research in agriculture: Better decisions for a scarce and uncertain world. The Journal of Agris on $\neg$ line Papers in Economics and Informatics, 5(2), 37-46.

[19] Sökmen, Y., \& Nalçaci, A. (2020). A Bibliometric Analysis of the Articles about Values Education. International Journal of Curriculum and Instruction, 12(2), 720-735.

[20] Pritchard, A. (1969). Statistical bibliography or bibliometrics. Journal of documentation, 25(4), 348-349.

[21] Erturgut, R., \& Yılmaz, B. (2020). Afet ve insani yardim lojistiği alanında yapılan çalışmaların bibliyometrik analizi. Pamukkale Üniversitesi Sosyal Bilimler Enstitüsü Dergisi, (40), 105-123.

[22] Andrés, A. (2009). Measuring academic research: How to undertake a bibliometric study. 1st ed., Oxford: Chandos Publishing.

[23] Bocanegra-Valle, A. (2014). 'English is my default academic language': Voices from LSP scholars publishing in a multilingual journal. Journal of English for Academic Purposes, 13, 65-77. 